Tropical Journal of Pharmaceutical Research January 2018; 17 (1): 135-141

ISSN: $1596-5996$ (print); 1596-9827 (electronic)

(c) Pharmacotherapy Group, Faculty of Pharmacy, University of Benin, Benin City, 300001 Nigeria.

\title{
Molecular characterization of carbapenem-resistant Acinetobacter baumannii isolated from pediatric burns patients in an Iranian hospital
}

\begin{abstract}
Abazar Pournajaf ${ }^{1}$, Ramazan Rajabnia ${ }^{2}$, Shabnam Razavi ${ }^{1,3}$, Sana Solgi ${ }^{1}$, Abdollah Ardebili ${ }^{4}$, Sajad Yaghoubi $^{5}$, Mahmoud Khodabandeh ${ }^{6}$, Yousef Yahyapour $^{2}$, Behzad Emadi ${ }^{7}$, Gholamreza Irajian ${ }^{1,3 *}$

${ }^{1}$ Department of Microbiology, Faculty of Medicine, Iran University of Medical Sciences, Tehran, ${ }^{2}$ Infectious Diseases and Tropical Medicine Research Center, Babol University of Medical Sciences, Babol, ${ }^{3}$ Microbial Biotechnology Research Center, Iran University of Medical Sciences, Tehran, ${ }^{4}$ Department of Microbiology, Faculty of Medicine, Golestan University of Medical Sciences, Gorgan, ${ }^{5}$ Division of Microbiology, Department of Pathobiology, School of Public Health, Tehran University of Medical Sciences, ${ }^{6}$ Department of Infectious Diseases, Pediatric's Center of Excellence, Children's Medical Center, Tehran University of Medical Sciences, ${ }^{7}$ Department of Microbiology, School of Medicine, Iran University of Medical Sciences, International Campus, Tehran, Iran
\end{abstract}

*For correspondence: Email: Dr.irajian@yahoo.com; Tel/Fax: +98-2188058649

\begin{abstract}
Purpose: To survey the molecular characteristics of imipenem-resistant Acinetobacter baumannii obtained from pediatric burns patients in a teaching hospital in Tehran, Iran.

Methods: Over a 10-month period, 73 non-duplicate A. baumannii strains were collected from pediatric burns patients admitted to Motahari Burn and Reconstruction Center, Tehran, Iran. The resistance profile of several antimicrobials was determined. Metallo- $\beta$-lactamase (MBL)-producing isolates were identified using double-disk synergy and an MBL E-test. Polymerase chain reaction (PCR) was carried out to detect the following $\beta$-lactamase-encoding elements: blaVIM, blaIMP, blaSIM, blaSPM, blaGIM, blaNDM, blaAIM, blaDIM, blaKPC, blaOXA-23/24/51, and blaOXA-58. The types of integrons were also identified using PCR.

Results: Out of the 73 collected strains, 92.4 and $38.3 \%$ of the isolates were multidrug-resistant (MDR) and extensively drug-resistant $(X D R)$, respectively. Colistin was the most effective antibiotic. It was found that $94.5 \%$ of the strains were resistant to imipenem, as determined both by disk agar diffusion and MIC E-test methods. Based on double disk synergy and E-test, 78.1 and $83.5 \%$ of the isolates, respectively, were MBL producers. The prevalence of blaOXA-23 and blaOXA-24 were 75.4 and 39.1 $\%$, respectively. The results also indicate that $62.3,30.4$, and $4.3 \%$ of the isolates were positive for blaVIM, blaIMP and blaNDM genes, respectively. Furthermore, $16.4,76.1$, and $7.5 \%$ of the isolates carried intl, intll, and intIII genes, respectively.

Conclusion: The increased frequency of carbapenem-resistant $A$. baumannii in burns cases underlines the importance of choosing an appropriate antibacterial regimen based on antibiotic susceptibility profile. Rapid identification of carbapenemase-producing strains would be helpful for selecting suitable antimicrobial therapy and preventing further spread of their encoding genes.
\end{abstract}

Keywords: Carbapenem-resistant Acinetobacter baumannii, Pediatric burns, Integron, $\beta$-lactamase genes

This is an Open Access article that uses a funding model which does not charge readers or their institutions for access and distributed under the terms of the Creative Commons Attribution License (http://creativecommons.org/licenses/by/4.0) and the Budapest Open Access Initiative (http://www.budapestopenaccessinitiative.org/read), which permit unrestricted use, distribution, and reproduction in any medium, provided the original work is properly credited.

Tropical Journal of Pharmaceutical Research is indexed by Science Citation Index (SciSearch), Scopus, International Pharmaceutical Abstract, Chemical Abstracts, Embase, Index Copernicus, EBSCO, African Index Medicus, JournalSeek, Journal Citation Reports/Science Edition, Directory of Open Access Journals (DOAJ), African Journal Online, Bioline International, Open-J-Gate and Pharmacy Abstracts 


\section{INTRODUCTION}

Burn wound infections are significant causes of morbidity and mortality, and they are ultimately responsible for $50-75 \%$ of deaths. Acinetobacter baumannii is widely dispersed as an important opportunistic pathogen, especially in burn patients, all over the world [1]. Increasing resistance in this bacterium complicates the selection of suitable empirical therapy in severe infections, such as burn wound injuries. The carbapenems are broadly regarded as a suitable option for the treatment of severe infections caused by multidrug-resistant $A$. baumannii (MR$A B)$ [2]. In the low-income countries, the incidence of carbapenem-resistant $A$. baumannii (CR-AB) infections is increasing at an alarming rate, especially among hospitalized burn patients [3].

Carbapenem resistance in $A$. baumannii is related to several combined mechanisms, such as the acquisition of $\beta$-lactamases, AmpC stable derepression, low outer membrane permeability, altered penicillin-binding proteins (PBPs), and less frequently, efflux pump overexpression [4]. Especially, oxacillinase (OXA)-type $\beta$-lactamases (Ambler class D enzymes) and metallo- $\beta$ lactamases (MBL; Ambler class B enzymes) have been identified worldwide from $C R-A B$ strains. MBL enzymes, including IMP, VIM, SPM, GIM, SIM, AIM, FIM, and NDM, are zincdependent carbapenemases; they are inhibited by EDTA and play a crucial role in drug resistance against carbapenems. OXAs, which are not inhibited by EDTA and/or clavulanic acid, are subdivided into six families, as follows: the OXA-23-like, OXA-24/40-like, OXA-51-like, OXA58-like, OXA-143-like, and OXA-182-like families $[4,5]$.

Carbapenemases have a high ability to spread, since their encoding genes have usually been found in transferable plasmids comprising integrons and insertion sequence (IS) determinants. Integrons are assembly genetic platforms/DNA segments that can gain gene cassettes carrying antibiotic-resistance elements via a site-specific recombination. These genetic elements are recognized by the presence of three essential apparatuses for producing exogenous genes, as follows: an integrase (intl gene), attl (a recombination site), and $\mathrm{P}_{\mathrm{C}}$ (a promoter). The most common types of integrons are transportable class I, followed by class II and III integrons [3,6]. In recent years, A. baumannii strains producing MBL-, OXA-, and KPC-type carbapenemases have been increasingly found in Iran [2]. This study was performed to determine the antibiotic resistance profiles and frequencies of MBL-, OXA-, and KPC-encoding determinants and int genes in $A$. baumannii isolated from pediatric burn patients in Tehran, Iran.

\section{EXPERIMENTAL}

\section{Ethical approval}

The study was approved by the ethical committee of Iran University of Medical Sciences (IUMS), Tehran, Iran (consent ref no. IR.IUMS.REC 1395.9221133207). Written informed consent form was collected from the patients or a close relative. Identifying information of each sample was kept secret. Each stage of sampling was done in such a way as to minimize pain and harm to the patients and international guidelines for human studies were followed [7].

\section{Sampling and bacterial isolates}

This cross-sectional study was performed on patients hospitalized at the pediatric ward of the Motahari Burn and Reconstruction Center in Tehran, Iran, from October 2016 to June 2017. The Motahari burn hospital is one of the specialized burn centers in our country, providing care to burn cases from Tehran (the capital of Iran) and patients with complications who have been referred from other therapeutic centers across the country. The hospital currently operates under the Iran University of Medical Sciences (IUMS). Burns patients were recruited according as per Bowler et al [1]. A. baumannii was initially identified using biochemical and microbiological procedures and then, confirmed using an API 20 NE Kit (version 6.0, bioMérieux, Marcy l'Étoile, France). Each isolate was preserved in Luria-Bertani broth (Merck Co., Germany) containing $20 \%$ glycerol ( $/ \mathrm{v})$ at -80 ${ }^{\circ} \mathrm{C}$ for further use. A. baumannii ATCC 19606 was used as a quality control.

\section{Antimicrobial susceptibility testing}

An antimicrobial susceptibility test was conducted using the disk agar diffusion (DAD) assay, as suggested by the Clinical and Laboratory Standards Institute (CLSI document M100-S14) [8], on Mueller-Hinton agar (MHA) plates for the 11 following antimicrobials: levofloxacin (LEV; $5 \mu \mathrm{g}$ ); ceftazidime (CAZ; 30 $\mu \mathrm{g})$, cefotaxime (CTX; $30 \mu \mathrm{g})$, piperacillin/tazobactam (TZP; $100 / 10 \mu g)$, imipenem (IPM; $10 \mu \mathrm{g}$ ), ciprofloxacin (CIP; $5 \mu \mathrm{g}$ ), tobramycin (TOB; $10 \mu \mathrm{g}$ ), gentamicin (GM; 10 $\mu \mathrm{g}$ ), piperacillin (PIP; $100 \mu \mathrm{g}$ ), tetracycline (TET; $30 \mu \mathrm{g}$ ), and trimethoprim-sulfamethoxazole

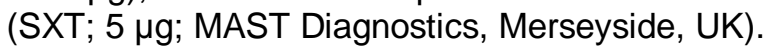


Multidrug-resistant (MDR), extensively drugresistant (XDR), and pan-drug-resistant (PDR) isolates were identified based on the guidelines suggested by the Centers for Disease Control and Prevention (CDC). Each strain was tested for colistin (CL) and IPM susceptibility using an E-test in line with the manufacturer's guidelines (Liofilchem SRL, Roseto degli Abruzzi, Italy). The Liofilchem MIC Test Strips (MTS) for colistin (CS; drug concentration gradient of $0.016-256$ $\mathrm{mg} / \mathrm{ml}$, with interpretative criteria of susceptible [S], $\leq 2 \mu \mathrm{g} / \mathrm{ml}$, resistant [R], $\geq 4 \mu \mathrm{g} / \mathrm{ml}$ ) and IPM (range: $0.002-32 \mu \mathrm{g} / \mathrm{ml}$, MIC interpretative criteria of $S, \leq 4 \mu \mathrm{g} / \mathrm{ml}, \mathrm{R}, \geq 16 \mu \mathrm{g} / \mathrm{ml}$ ) were used. The strips were placed onto MHA medium with an added bacterial suspension equal to 0.5 McFarland. After incubation at $37^{\circ} \mathrm{C}$ for $18-24$ $\mathrm{h}$, E-test MICs were determined as the point of interception of the zone of inhibited growth with the strips.

\section{Identification of the MBL phenotype}

For the identification of MBL-producing isolates, a combined disk diffusion test (CDDT) was performed. Concisely, a 0.5 McFarland turbidity of the bacterial suspension was streaked on an MHA plate. Then, two 10- $\mu \mathrm{g}$ IPM disks were placed on the MHA plates; following this, $10 \mu \mathrm{L}$ of MBL inhibitor solution (0.5 M EDTA) was added to one of the IPM disks to reach a desired concentration of $750 \mathrm{mg}$. After $24 \mathrm{~h}$ of incubation at $35{ }^{\circ} \mathrm{C}$, the inhibition zone diameters of all disks were recorded and compared. The isolates were considered MBL-producing isolates when the difference in the inhibition zones was observed to be $\geq 7 \mathrm{~mm}$. In addition, $\mathrm{MBL}$ E-test MIC values (IPM [range: $4-256 \mu \mathrm{g} / \mathrm{mL}$ ] and IPM/EDTA [IMD; range: $1-64 \mu \mathrm{g} / \mathrm{mL}$; Liofilchem SRL) was done according to the company's instructions. An IPM/IMD ratio $\geq 8$ $\mu \mathrm{g} / \mathrm{L}$ was considered positive.

\section{Modified hodge test (MHT)}

The Modified Hodge test (MHT) was performed in all IPM-resistant isolates according to the CLSI guideline to identify carbapenemase-producing organisms. An overnight suspension of Escherichia coli ATCC 25922 equivalent to the turbidity of the 0.5 McFarland standard was streaked on MHA using a sterile cotton swab. Then, a 10- $\mathrm{gg}$ meropenem disk (HI-MEDIA, Mumbai, India) was placed at the center of the petri dish, and the test isolate was cultured from the edge of the disk to the margin of the plate in four orders. The presence of a 'cloverleafshaped' inhibition zone after $24 \mathrm{~h}$ incubation at $37^{\circ} \mathrm{C}$ was considered as a positive test result.

\section{Polymerase chain reaction (PCR)}

A DNA Extraction Kit (Bioneer Company, Korea, Cat. number K-3032-2) was used to extract genomic DNA from the colonies grown overnight in brain heart infusion agar plates. The concentration and quality of the total genomic DNA extracted were evaluated using a NanoDrop ${ }^{\text {TM }} 1000$ Spectrophotometer (Thermo Scientific, Wilmington, DE, USA). DNA isolates with a concentration of $0.1 \mathrm{ng} / \mu \mathrm{l}$ were used as the templates for polymerase chain reaction (PCR) assay. The oligonucleotide primer sequences used for amplification of target genes,

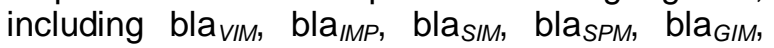
bla $_{N D M}$, bla $_{A I M}$, bla $_{D I M}$, bla $_{K P C}$, bla $a_{O X A-23 / 24 / 51 / 58}$ and int are recorded in Table 1. The PCR mixture was carried out in a final volume of $25 \mu \mathrm{l}$, including the following ingredients: $0.5 \mu \mathrm{l}$ of bacterial DNA extract; $2 \mu \mathrm{l}$ of $10 \times$ PCR buffer; $1.8 \mathrm{mmol} / \mathrm{l}$ of $\mathrm{MgCl}_{2} ; 0.8 \mu \mathrm{l}$ (each) of dATP, dGTP, dCTP, and dTTP; $0.7 \mu$ of each primer; $0.8 \mu \mathrm{l}$ of Taq DNA polymerase $(5 \mathrm{U} / \mu \mathrm{l}$; Amplicon Co., Denmark); and $15.3 \mu \mathrm{l}$ of $\mathrm{dd}_{2} \mathrm{O}$. The genes were amplified in a Techne TC-512 thermocycler (Eppendorf, Hamburg-Nord, Germany), as follows: initial denaturation at $95^{\circ} \mathrm{C}$ for $3 \mathrm{~min}, 35$ cycles of denaturation for $50 \mathrm{~s}$ at $95{ }^{\circ} \mathrm{C}$, annealing for $40 \mathrm{~s}$ at $55^{\circ} \mathrm{C}$, and extension for $120 \mathrm{~s}$ at $72{ }^{\circ} \mathrm{C}$, as well as a final extension for 5 min at $72{ }^{\circ} \mathrm{C}$. PCR amplicons were subjected to electrophoresis in a $1.5 \%$ agarose gel for $2 \mathrm{~h}$ at $70 \mathrm{~V}$ with a 100-bp size marker (Fermentas Co., Lithuania), stained with Gel Red'M (Biotium, USA), and photographed with ultraviolet illumination (Bio-rad, Hercules, USA).

\section{RESULTS}

In general, 73 non-duplicative burned wound samples were collected from the patients $(n=41$, $56.2 \%$ female; $n=32,43.8 \%$ male). The mean age of the patients studied was 8.5 years, with a range of $4-17$ years. The antimicrobial susceptibility results are shown in Table 2 . The frequencies of MDR and XDR isolates were 92.4 and $38.3 \%$, respectively. Moreover, $94.5 \%(n=$ $69 / 73$ ) of the strains were resistant to IPM, as determined by both the DAD and MIC E-test methods. The results of the E-test showed that $\mathrm{CL}$ was the most effective antimicrobial, with a susceptibility rate of $98.6 \%$. Only $1.4 \%(n=1)$ of the isolates were resistant to CL in the MTS with the interpretative criterion of $\geq 4 \mu \mathrm{g} / \mathrm{ml}$. Among the 69 IPM-resistant $A$. baumannii, 82.6 $\%(n=57)$ and $88.4 \%(n=61)$ were MBL producers, as determined by the CDDT and Etest methods, respectively. 
Table 1: Oligonucleotide primer sequences used in this study

\begin{tabular}{|c|c|c|c|}
\hline Target gene & Primer sequence $\left(5^{\prime} \rightarrow 3^{\prime}\right)$ & Product size (bp) & Reference \\
\hline intl & $\begin{array}{l}\text { F=5'-GGTGTGGCGGGCTTCGTG-3' } \\
\text { R=5'-GCATCCTCGGTTTTCTGG-3' }\end{array}$ & 457 & [9] \\
\hline intll & $\begin{array}{l}\mathrm{F}=5^{\prime} \text { CACGGATATGCGACAAAAAGGT -3' } \\
\mathrm{R}=5^{\prime}-\mathrm{GTAGCAAACGAGTGACGAAATG}-3^{\prime}\end{array}$ & 789 & \\
\hline intIII & 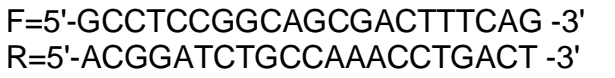 & 980 & \\
\hline IMP & $\begin{array}{l}\text { F=5'- TGAGCAAGTTATCTGTATTC-3' } \\
\text { R=5'- TTAGTTGCTTGGTTTTGATG-3' }\end{array}$ & 740 & [10] \\
\hline$S P M$ & $\begin{array}{l}\mathrm{F}=5^{\prime}-\text { CCTACAATCTAACGGCGACC-3' } \\
\mathrm{R}=5^{\prime}-\text { TCGCCGTGTCCAGGTATAAC-3' }\end{array}$ & 674 & \\
\hline VIM & $\begin{array}{l}\text { F=5'- AAAGTTATGCCGCACTCACC-3' } \\
\text { R=5'- TGCAACTTCATGTTATGCCG-3' }\end{array}$ & 815 & \\
\hline NDM & $\begin{array}{l}\text { F=5'- GGTTTGGCGATCTGGTTTTC-3' } \\
\text { R=5'- CGGAATGGCTCATCACGATC-3' }\end{array}$ & 627 & [11] \\
\hline DIM & $\begin{array}{l}\text { F=5'- GCTTGTCTTCGCTTGCTAACG-3' } \\
\text { R=5'- CGTTCGGCTGGATTGATTTG-3' }\end{array}$ & 699 & [12] \\
\hline AIM & $\begin{array}{l}\mathrm{F}=5^{\prime}-\text { CTGAAGGTGTACGGAAACAC-3' } \\
\mathrm{R}=5^{\prime}-\text { GTTCGGCCACCTCGAATTG-3' }\end{array}$ & 322 & \\
\hline GIM & $\begin{array}{l}\mathrm{F}=5^{\prime}-\text { TCGACACACCTTGGTCTGAA-3' } \\
\mathrm{R}=5^{\prime}-\text { AACTTCCAACTTTGCCATGC-3' }\end{array}$ & 477 & \\
\hline SIM & $\begin{array}{l}\mathrm{F}=5^{\prime}-\text { TACAAGGGATTCGGCATCG-3' } \\
\text { R=5'- TAATGGCCTGTTCCCATGTG-3' }\end{array}$ & 570 & \\
\hline OXA-23-like & $\begin{array}{l}\mathrm{F}=5^{\prime}-\text { GATCGGATTGGAGAACCAGA-3' } \\
\text { R=5'- ATTTCTGACCGCATTTCCAT-3' }\end{array}$ & 501 & [11] \\
\hline OXA-24-like & 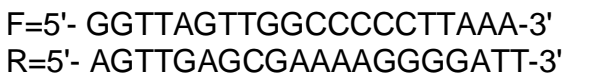 & 246 & \\
\hline OXA-85-like & $\begin{array}{l}\mathrm{F}=5^{\prime}-\text { AAGTATTGGGGCTTGTGCTG-3' } \\
\mathrm{R}=5^{\prime}-\text { CCCCTCTGCGCTCTACATAC-3' }\end{array}$ & 599 & \\
\hline OXA-51-like & $\begin{array}{l}\text { F=5'- TAATGCTTTGATCGGCCTTG-3' } \\
\text { F=5'- TGG ATTGCACTTCATCTTGG-3' }\end{array}$ & 353 & [13] \\
\hline$K P C$ & $\begin{array}{l}\text { F=5'- CTTGCTGCCGCTGTGCTG -3' } \\
\text { R=5'- GCAGGTTCCGGTTTTGTCTC -3' }\end{array}$ & 489 & \\
\hline
\end{tabular}

MBL genes detected in this study were bla ${ }_{V I M}(n$ $=43,62.3 \%)$, bla $\operatorname{la}_{M P}(n=21,30.4 \%)$, and bla ${ }_{N D M}$ ( $n=3,4.3 \%)$. The coexistence of bla ${ }_{M P}$ and bla ${ }_{V I M}$ was observed in $10.4 \%$ of isolates $(n=$ $7 / 69)$. Only $4.3 \%(n=3 / 69)$ of IPM-resistant $A$. baumannii were negative for MBL activity and the genes tested. No amplicons were obtained with the primer detecting the bla $\mathrm{a}_{D I M}$, bla $\mathrm{a}_{S I M}$, bla $\mathrm{a}_{A I M}$, and bla sPM $_{\text {genes. }}$

In this study, all isolates harbored the bla OXA-51-like gene, intrinsic to $A$. baumannii strains. Out of 69 CR-AB isolates, $75.4 \%(n=52)$ and $39.1 \%(n=$ 27) were found to harbor the bla $O X A-23$-like and bla $O X A-24$-like genes, respectively. The coexistence of the bla OXA-23-like $_{\text {and }}$ bla OXA-24-like $_{\text {genes occurred }}$ in $17.4 \%(n=12 / 69)$ of isolates. No isolates were positive for the bla oXA-58-like $_{\text {gene. }}$

In the MHT, $13 \%(n=9 / 69)$ of the strains were positively identified as KPC-producing isolates, as they developed a cloverleaf shape; however, only $5.8 \%(n=4 / 69)$ of isolates carried the bla $_{K P C}$ gene. The Int gene was found in $91.7 \%$ ( $n$ $=67 / 73$ ) of the isolates.

The molecular analyses of class I, II, and III integrons showed that $16.4 \%(n=11 / 67), 76.1$ $\%(n=51 / 67)$, and $7.5 \%(n=5 / 67)$ of the strains harbored the intl, intll, and intlll genes, respectively. The coexistence of int//int/l and intl/int/I/int/II in isolates were $11.9 \%(n=8)$ and $2.9 \%(n=2)$, respectively.

Table 2: Antimicrobial susceptibility profile of $A$. baumannii isolates

\begin{tabular}{lccc}
\hline $\begin{array}{l}\text { Antimicrobial } \\
\text { agent }\end{array}$ & \multicolumn{3}{c}{$\begin{array}{c}\text { Antimicrobial susceptibility, N } \\
(\%)\end{array}$} \\
\cline { 2 - 4 } & $\mathbf{S}$ & $\mathbf{I}$ & $\mathbf{R}$ \\
\hline TZP & $1(1.4)$ & $0(0.0)$ & $72(98.6)$ \\
CIP & $0(0.0)$ & $0(0.0)$ & $73(100)$ \\
CTX & $0(0.0)$ & $0(0.0)$ & $73(100)$ \\
CAZ & $2(2.7)$ & $0(0.0)$ & $71(97.3)$ \\
IPM & $4(5.5)$ & $0(0.0)$ & $69(94.5)$ \\
PIP & $0(0.0)$ & $0(0.0)$ & $73(100)$ \\
TOB & $1(1.4)$ & $1(1.4)$ & $71(97.3)$ \\
TET & $3(4.1)$ & $0(0.0)$ & $70(95.9)$ \\
GM & $2(2.7)$ & $1(1.4)$ & $70(95.9)$ \\
LEV & $1(1.4)$ & $0(0.0)$ & $72(98.6)$ \\
SXT & $0(0.0)$ & $0(0.0)$ & $73(100)$ \\
\hline
\end{tabular}

LEV; levofloxacin, CAZ; ceftazidime, CTX; cefotaxime, TZP; piperacillin/tazobactam, PIP; Piperacillin, IPM; imipenem, CIP; ciprofloxacin, TOB; Tobramycin, GM; gentamicin, TET; tetracycline, SXT trimethoprimsulphamethoxazole, S; susceptible, I; intermediate, $R$; resistant 


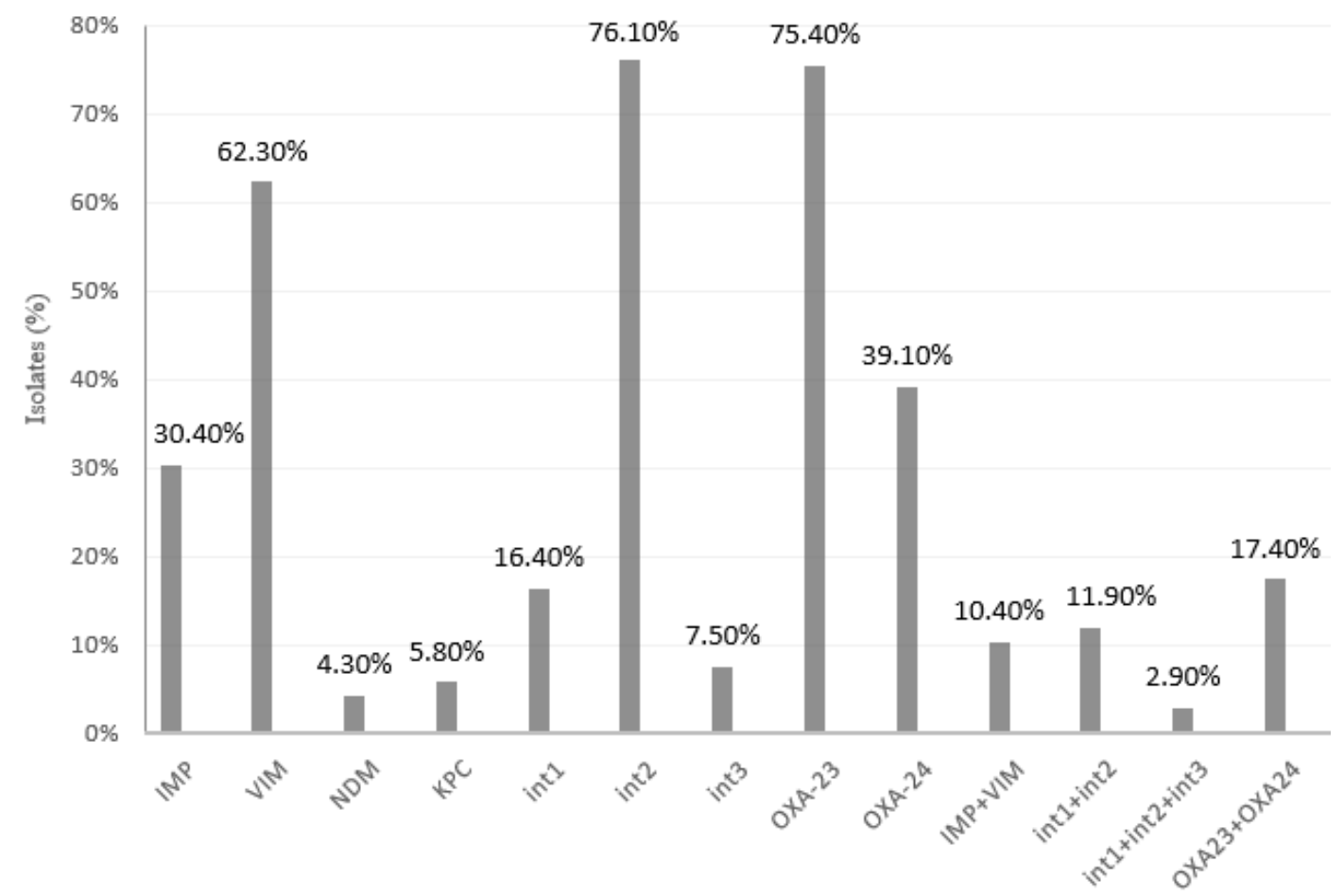

Figure 1: Distribution of genes encoding carbapenemases and integrase in A. baumannii isolated from pediatric burns patients.

\section{DISCUSSION}

The rapid emergence of MDR-AB and XDR-AB strains in recent years has become an important concern for treatment of hospital acquired infections, especially in burn patients [7]. The results of this study, which supported the findings of other studies [14,15], revealed the presence of A. baumannii strains with multiple resistances to antimicrobials in our hospital. Furthermore, we found a high resistance rate to carbapenems $(94.5 \%)$, a class of antibiotics that used to be the drug of choice. Similarly, Shoja et al [11] showed that $92.5 \%$ of $A$. baumannii isolated from burn patients were resistant to carbapenems, and therefore, these agents are not suitable for the treatment of infections.

Polymyxins, such as $\mathrm{CL}$, are effective agents against the overwhelming majority of $A$. baumannii throughout the world. In a systematic review study conducted by Razavi et al [16], polymyxins showed adequate activity against $A$. baumannii isolated from 2006 to 2013; in their results, $77-100 \%$ of isolates were susceptible to CL. Furthermore, they found no significant change in the resistance of isolates to this antibiotic during the study period. Similarly, we found that $98.6 \%$ of isolates were susceptible to $\mathrm{CL}$. These findings indicate that $\mathrm{CL}$ has increasingly become the last viable therapeutic choice for MDR-AB infections.
It has been suggested that OXA-type carbapenemases play an important role in carbapenem resistance in $A$. baumannii. Outbreaks of CR-AB harboring the bla ${ }_{O X A-23-l i k e}$ gene occurs in $31 \%$ to $100 \%$ worldwide [12]. The prevalence of the bla OXA-23-like and bla OXA-24like genes in the current study were 75.4 and 39.1 $\%$, respectively. Quiñones et al [17] showed that $75 \%$ of CR-AB isolates harbored different bla $O X A$ genes (bla OXA-23: $73 \%$, bla OXA-24: $18 \%$, bla OXA-58: $3 \%$, which suggests that these OXAs may be locally spread. Moreover, Farshadzadeh et al [18] showed that the broad distribution of the blaoxA-23-like gene was the main reason for the rapid increase in the carbapenem resistance rate among burn patients in Iran.

It has been reported that when screening for carbapenemases, two confounders must be ruled out, as follows: (I) not all carbapenemresistant strains produce a carbapenemase, and (ii) not all carbapenemase producers are resistant to carbapenems [19]. The carbapenemresistant strains in this study were screened using the MHT and IMD methods, which have been effectively used to validate carbapenemase producers. These tests can also discriminate carbapenem-resistance mediated by carbapenemases from that mediated by other mechanisms. The present study showed that carbapenem-resistance was chiefly caused by MBLs. However, the observed low rates of carbapenemase activity in MHT among CR-AB 
could have emerged because the identification of carbapenemase activity in clinical strains is challenging [20]; the MHT method suffers from low sensitivity, and interpretation of its results can be subjective (the cloverleaf indentation). Thirteen percent of KPC-producing isolates were found phenotypically, but only $5.8 \%$ of isolates were positive for the bla $a_{K P C}$ gene. This contrast may have been due to reduced susceptibility to at least one extended-spectrum cephalosporin and another mechanism, such as carbapenem resistance due to a combination of an extendedspectrum beta-lactamases (ESBLs) or AmpCtype enzyme with porin loss [21].

In the present study, bla ${ }_{V I M}$ was the most prevalent MBL-encoding gene tested $(62.3 \%)$, followed by bla $\mathrm{I}_{M P}(30.4 \%)$ and bla $\mathrm{a}_{N D M}(4.3 \%)$. In a study performed by Fallah et al [22], 17.4 and $3.5 \%$ of $A$. baumannii isolates were positive for the bla ${ }_{V I M}$ and bla $_{I M P}$ genes, respectively. Yousefi et al [9] showed that bla IMP was more important, especially among the clinical isolates of Pseudomonas aeruginosa in Iran. Regarding the relatively high frequency of bla $\mathrm{a}_{N D}$ in our study, it is important to note that bla NDM $_{N}$ was primarily recognized in India, and only later was it reported from other countries, such as Pakistan. The proximity of these countries to Iran and the large number of visits and immigration between the states on the one hand and the ease of resistance transfer among the organisms on the other led us to think that it may be feasible for our strains to have a similar gene. In concordance with Fallah et al [22], these studies are valuable for preventing the spread of resistant organisms to other parts of the world.

In this work, $91.7 \%$ of $A$. baumannii isolates carried genes encoding integrase, a necessary element for integron functions. Our results showed that class II integron was the most prevalent in our isolates, which agreed with the results of Deylam Salehi et al [14] and Mirnejad et al [23], but contrasted with the reports of Lin et al [24] and Taherikalani et al [15]. Chen et al [25] showed that detection of integrons is an indicator for evaluating MDR-AB epidemics. The differences in the prevalence of integron types in previous studies and the present one are most likely owing to the geographical distance, surveillance strategies, and restraint in antibiotic prescriptions in other regions.

\section{CONCLUSION}

The findings of this study demonstrate a high prevalence of CR-AB isolates that carry various encoding genes and could produce carbapenemases at the study site. Rapid and precise identification of these strains is necessary for selection of suitable antimicrobial therapy, controlling their inter- or intra-hospital spread, and ultimately, diminishing related infections, especially in burn patients.

\section{DECLARATIONS}

\section{Acknowledgement}

This work was supported by Iran University of Medical Sciences (contract no. 27733) and Babol University of Medical Sciences (contract no. 9542125). The authors would also like to thank the staff of Motahari Burn and Reconstruction Center (Tehran, Iran) for kindly providing clinical isolates.

\section{Conflict of interest}

There is no conflict of interest associated with this work.

\section{Contribution of the authors}

We declare that this work was carried out by the authors named in this article, and all liabilities pertaining to claims relating to the content of this article will be borne by the authors. Conceived and designed the experiments (supervisor): Prof. Gholamreza Irajian. Performed the experiments: Abazar Pournajaf. Analyzed the data: Dr. Shabnam Razavi, Dr. Yousef Yahyapour, and Dr. Ramazan Rajabnia. Wrote the paper: Abazar Pournajaf, Dr. Abdollah Ardebili, and Dr. Azadeh Alvandimanesh. Sampling: Sana Solgi and Yousef Erfani. Clinical consulting: Dr. Mahmoud Khodabandeh and Dr. Mohammad Reza Abdolsalehi.

\section{REFERENCES}

1. Bowler $P$, Duerden $B$, Armstrong DG. Wound microbiology and associated approaches to wound management. Clin Microbiol Rev 2001; 14(2): 244-269.

2. Ardebili A, Lari AR, Beheshti M, Lari ER. Association between mutations in gyrA and parC genes of Acinetobacter baumannii clinical isolates and ciprofloxacin resistance. Iran J Basic Med Sci 2015; 18(6): 623-626.

3. Taherikalani M, Fatolahzadeh B, Emaneini M, Soroush S, Feizabadi MM. Distribution of different carbapenem resistant clones of Acinetobacter baumannii in Tehran hospitals. New Microbiol 2009; 32(3): 265-271.

4. Naas $T$, Oueslati S, Bonnin RA, Dabos ML, Zavala A, Dortet $L$, Retailleau $P$, lorga BI. Beta-lactamase database (BLDB)-structure and function. J Enzyme Inhib Med Chem 2017; 32(1): 917-919. 
5. Gillings MR. Class 1 integrons as invasive species. Curr Opin Microbiol 2017; 38: 10-15.

6. Deng Y, Bao X, Ji L, Chen L, Liu J, Miao J, Chen D, Bian $\mathrm{H}, \mathrm{Li} Y$. Resistance integrons: class 1, 2 and 3 integrons. Ann Clin Microbiol Antimicrob 2015; 14: 45.

7. Ethics and research on human subjects: International guidelines. J Med Ethics 1995; 21(6): 363-364.

8. CLSI. Performance Standards for Antimicrobial Susceptibility Testing. 27th ed. CLSI supplement M100. Wayne, PA: Clinical and Laboratory Standards Institute. 2017.

9. Yousefi S, Farajnia S, Nahaei MR, Akhi MT, Ghotaslou $R$, Soroush $M H$, Naghili B, Jazani NH. Detection of metallo- $\beta$-lactamase-encoding genes among clinical isolates of Pseudomonas aeruginosa in northwest of Iran. Diagn Microbiol Infect Dis 2010; 68(3): 322-325.

10. Moosavian M, Rahimzadeh M. Molecular detection of metallo- $\beta$-lactamase genes, blalMP-1, blaVIM-2 and blaSPM-1 in imipenem resistant Pseudomonas aeruginosa isolated from clinical specimens in teaching hospitals of Ahvaz, Iran. Iran J Microbiol 2015; 7(1): 2-6.

11. Shoja S, Moosavian M, Rostami S, Farahani A, Peymani A, Ahmadi K, Ebrahimifard N. Dissemination of carbapenem-resistant Acinetobacter baumannii in patients with burn injuries. J Chin Med Assoc 2017; 80(4): 245-252.

12. Tarashi S, Goudarzi H, Erfanimanesh S, Pormohammad A, Hashemi A. Phenotypic and Molecular Detection of Metallo-Beta-Lactamase Genes Among Imipenem Resistant Pseudomonas aeruginosa and Acinetobacter baumannii Strains Isolated From Patients with Burn Injuries. Arch Clin Infect Dis 2016; 11(4):e39036.

13. Safari M, Mozaffari NAS, Bahador A, Jafari R, Alikhani $M Y$. Prevalence of ESBL and MBL encoding genes in Acinetobacter baumannii strains isolated from patients of intensive care units (ICU). Saudi J Biol Sci 2015; 22(4): 424-429.

14. Deylam Salehi M, Ferdosi-Shahandashti E, Yahyapour Y, Khafri S, Pournajaf A, Rajabnia R. Integron-Mediated Antibiotic Resistance in Acinetobacter baumannii Isolated from Intensive Care Unit Patients, Babol, North of Iran. Biomed Res Int 2017.

15. Taherikalani M, Maleki A, Sadeghifard $N$, Mohammadzadeh $D$, Soroush $S$, Asadollahi $P$, Asadollahi K, Emaneini M. Dissemination of class 1, 2 and 3 integrons among different multidrug resistant isolates of Acinetobacter baumannii in Tehran hospitals, Iran. Pol J Microbiol 2011; 60(2): 169-174.

16. Razavi NH, Ardebili A, Mardaneh J. Systematic Review of Antimicrobial Resistance of Clinical Acinetobacter baumannii Isolates in Iran: An Update. Microb Drug Resist 2017; 23(6): 744-756.

17. Quiñones D, Carvajal I, Perez Y, Hart M, Perez J, Garcia S, Salazar D, Ghosh S, Kawaguchiya M, Aung MS, et al. High prevalence of bla OXA-23 in Acinetobacter spp. and detection of bla NDM-1 in A. soli in Cuba: report from National Surveillance Program (2010-2012). New Microb New Infect 2015; 7: 52-56.

18. Farshadzadeh Z, Hashemi FB, Rahimi S, Pourakbari B, Esmaeili D, Haghighi MA, Majidpour A, Shojaa $S$, Rahmani $M$, Gharesi $S$, et al. Wide distribution of carbapenem resistant Acinetobacter baumannii in burns patients in Iran. Front Microbiol2015; 6: 1146.

19. Kateete DP, Nakanjako R, Namugenyi J, Erume J, Joloba ML, Najjuka CF. Carbapenem resistant Pseudomonas aeruginosa and Acinetobacter baumannii at Mulago Hospital in Kampala, Uganda (2007-2009). SpringerPlus 2016; 5(1): 1308.

20. Queenan AM, K. Bush. Carbapenemases: the versatile B-lactamases. Clin Microbiol Rev 2007; 20(3): 440-458.

21. Bina M, Pournajaf A, Mirkalantari S, Talebi M, Irajian G. Detection of the Klebsiella pneumoniae carbapenemase $(K P C)$ in $K$. pneumoniae Isolated from the Clinical Samples by the Phenotypic and Genotypic Methods. Iran J Pathol 2015; 10(3): 199-205.

22. Fallah $F$, Noori $M$, Hashemi $A$, Goudarzi $H$, Karimi $A$, Erfanimanesh $S$, Alimehr $S$. Prevalence of blaNDM, blaPER, blaVEB, blaIMP, and blaVIM genes among Acinetobacter baumannii isolated from two hospitals of Tehran, Iran. Scientifica 2014; 6.

23. Mirnejad R, Mostofi S, Masjedian F. Antibiotic resistance and carriage class 1 and 2 integrons in clinical isolates of Acinetobacter baumannii from Tehran, Iran. Asian Pac J Trop Biomed 2013; 3(2): 140-145.

24. Lin MF, Chang KC, Yang CY, Yang CM, Xiao CC, Kuo HY, Liou ML. Role of integrons in antimicrobial susceptibility patterns of Acinetobacter baumannii. Jpn J Infect Dis 2010; 63(6): 440-443.

25. Chen J, Li H, Yang J, Zhan R, Chen A, Yan $Y$. Prevalence and characterization of integrons in multidrug resistant Acinetobacter baumannii in Eastern China: a multiple-hospital study. Int J Environ Res Public Health 2015. 12(8): 10093-10105. 